\title{
FORUM
}

\section{Some Suggestions on the Rules for Preventing Collision at Sea}

A paper by Captain J. F. Kemp under this title was published in the April number of this Journal together with some comments on these proposals. Further contributions to the discussion and a reply from Captain Kemp are printed below.

\section{Commandant L. Oudet writes:}

In the April issue of this Journal1 Captain Kemp has put forward a carefully considered proposal for making the Rule of the Road more effective. His proposal is well considered because he is aware of the audacity which its careful presentation conceals; he is also careful to suggest a change in the Rules only as a basis for discussion. His suggestion is precise, for it is simply to extend Rule i 8 to all encounters, or in other words to require both vessels, when crossing or overtaking, to rotate the line of sight in the normal direction as required in Rule 18.

Captain Wylie has pointed out very clearly that this suggestion cannot be accepted without dangerously departing from the spirit of the Rules. One could be even more emphatic, for the Rules themselves categorically refuse to make a division of responsibility, or to impose a particular rotation of the line of sight, except for vessels on opposite courses. The responsibility is placed on one of the parties and, in crossing, the normal (anti-clockwise) rotation of the sight line is preferred.

This in no way lessens the interest of Captain Kemp's proposal and the present author is particularly grateful to him for having added a new realism to the study of the basis of the Rules. 2 Because they are so clear and so challenging, Captain Kemp's ideas are just what we need to stimulate the minds of navigators and such a stimulus is badly needed. This is no doubt what he means when he says that he himself had been stimulated by the recent mathematical work on the collision problem and encouraged 'to take the bull by the horns'.

Under the same mathematical stimulus, one may say that his suggested amendment, in the terminology used by Calvert and Hollingdale, tends to make all crossing and overtaking positive by combining two positive manœuvres. Captain Wylie has pointed out the danger which may arise in Kemp's Case III (Fig. 3 b)
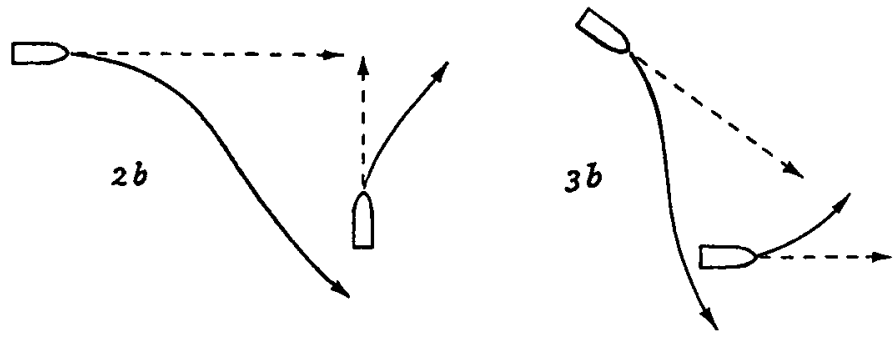

FIG. 1 . 
and Commander Clissold has pointed out the danger in his Case II (Fig. 2b). This is not surprising, for the recent mathematical work has made it clear that the infinite variety of encounters that may arise at sea does not yield to a uniform. treatment. In addition to the three types of encounter defined in the Rulesopposite courses, crossing, and overtaking-there is a classification which depends on the initial rotation of the line of sight-positive, neutral and negative.

Collisions almost always arise when the two parties do not agree in their classification. Captain Kemp's proposed amendment should prevent disagreements in the classification defined by the Rules, rather than disagreements. relating to the rotation of the line of sight. What seems impossible to accept is the necessity for a positive rotation when the initial situation constitutes a negative rotation. And even if one does accept this it does not solve the problem, as. there will still be cases where one of the parties considers the separation sufficient for a negative crossing while the other wishes to make it a positive crossing.

The possibility of both negative and positive rotations is inherent in the situation at sea, where traffic is not restricted to defined routes. To resolve any doubt. in marginal cases the Rules seem to have adopted the only possible solution, in assigning the responsibility to one of the vessels concerned; the other, which is required to maintain her course and speed, being treated as the privileged vessel.

But, as in any system which confers a privilege, there is the risk of encouraging the privileged vessel to do nothing. If she should continue to do nothing until she is cut in half, in spite of the desperate remedy provided by Rule $2 \mathrm{I}$, her privileged position is a poor consolation. 3 One should not therefore despise any attempt to. divide the weight of responsibility between the two parties to an encounter; to. divide it equally is perhaps too much but to propose some division of responsibility is certainly a good idea.

It should be noted, too, that the Rules themselves make a division of responsibility in fog (Rule 16) and in visual encounters on opposite courses (Rule 18 ). In the latter case they base the agreement between the parties on a normal, or positive, rotation of the line of sight. In crossings the Rules retain a preference for the positive rotation, but place a special responsibility on one of the vessels while leaving her free to choose the manœuvre she is going to execute. This unfortunately tends to make the privileged vessel consider herself free from all responsibility. The Rules are, however, both sensible and flexible (Rules 21 , 27 and 29) and do not countenance this privileged inertia. 2 They suggest manouvres like that shown in Fig. $2 \mathrm{~b}$ (p. 5 I I) for the privileged vessel, and ships on the Calais-Dover run, to give but one example, adopt them every day in crossing the main shipping routes in the Strait. They are carried out, of course, within the spirit of the Rules, but frankly to resolve the doubts and indecisions of other parties.

As for overtaking, the Rules are perhaps even easier to interpret for they assign the main responsibility to the faster ship; thus giving full weight to Calvert's pertinent remark that, for a fast ship a slower ship is merely an obstruction. This remark, which can often be applied to crossings, should always govern overtakings. There is no preference for the normal rotation of the line of sight, as. overtaking on the road clearly shows-in countries where one drives on the right one overtakes on the left.

The comparison between motor-cars and ships cannot be pressed very far, and it would be foolish to arrange for crossings to be negative because other encounters 
are usually positive; this is clear enough if one considers that, in overtaking, relative speed is more important than the sense of rotation. Manœuvres which conform to the spirit of the Rules are shown in Figs. $3 \mathrm{C}$ and $4 \mathrm{C}$; one can see in both cases

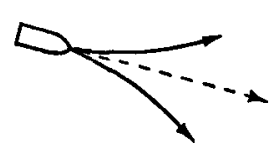

$3 c$

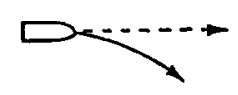

that the overtaking vessel is free to choose the direction of rotation, whereas the overtaken vessel can simply assist the manœuvre by steering a parallel course.

In conclusion, it seems that the Rules constitute a closely knit system in which it would be rash to change one essential component. But, on the other hand, we should neglect no attempt to demonstrate to navigators that the system is not rigid and that its fundamental principles always provide the necessary clue in difficult cases. Captain Kemp's contribution to this demonstration deserves further careful study.

\section{REFEREN CES}

1 Kemp, J. F. (1965). Some suggestions on the rules for preventing collisions at sea. This Journal, 18, 233.

2 Oudet, L. (1962). The principles underlying the collision regulations. This Journal, 15,402 .

3 Oudet, L. (1960). Radar and Collision, p. 56.

\section{Professeur P. Hugon (General Secretary, French Institute of Navigation) writes:}

It was a praiseworthy move by Captain Kemp to 'take the bull by the horns' and hope to establish new Rules, based on the recent mathematical studies, for the avoidance of collision in visual encounters. Nevertheless our curiosity remains unsatisfied, for the author recognizes that such far-reaching changes may not be either practicable or acceptable and that, because of the human factor, it may be necessary to adapt or amend the existing Rules since we cannot risk everything on the marvels of mathematics or on such perfect diagrams as Calvert's.

Above all, we cannot go on limiting the problem by saying that we are only concerned with visual encounters. In spite of the evidence there is too much confusion about this and too many vain attempts to define the privileged and the responsible ship in conditions of fog. Some of the difficulties arising from Captain Kemp's proposals have already been clearly demonstrated by Captain Wylie, Commander Clissold and Captain Azad.

Although criticism of the complexity of the existing Rules may now be the fashion, they seem to be the best that have yet been devised for anticipating the unforeseen and something is still to be said in their favour. 
Certainly the privileged status of the stand-on ship might become hard to bear if, in the light of Rule 21 , she were obliged to maintain her course 'to the bitter end', as one may say. The qualifications which accompany this injunction are open to endless criticism. At what moment does the privileged vessel acquire the right to decide that the danger of collision is imminent and to relinquish her irksome privilege? If she leaves it too late will she not find herself suddenly faced with a last-minute manœuvre by the vessel whose responsibility it is to make just such a move?

In fact the justification seems to be simple enough. The responsibility cannot be duplicated or divided without delaying indefinitely the carrying out of a manouvre, on the very good pretext of waiting to see what the other ship is going to do, or in the false hope of leaving the initiative to her. It is therefore right that a rule should determine clearly which ship carried the burden of responsibility and the obligation to manœuvre.

In exchange, the other ship is required to maintain her course and speed, otherwise the ship bearing the burden of responsibility would not know how to manœuvre. The story should logically end there, and no rule should be so worded as to throw doubt on its own purpose and provide for cases where it can be ignored, otherwise it becomes no more than a sort of insurance against all eventualities and an attempt to provide against all the uncertainties of human error.

It is hopeless to try to provide for every case, even when the Rule itself has been ignored to the verge of disaster. Why should one stop there when one can carry legislation to the point of absurdity by saying that if the privileged vessel makes a mancuvre at the last moment, because the other vessel has not yet done so, and if the latter wakes up, she should then maintain her course and speed, and so on. Fortunately Rule 29, which majestically covers all eventualities, does not impose any rigid solution but, taking into account all the imponderables, relies on the common sense of the sailor to take the best action possible.

\section{Captain J. García-Frías (Spanish Navy) writes:}

I agree with Captain Kemp that 'the Rules as they stand are not entirely satisfactory'. Seven years ago1 I demonstrated some of these imperfections and I suggested that they could be solved by a Sector Rule similar to one I proposed for using radar in fog. 2 I also agree with Captain Kemp that 'responsibility should continue to be assigned initially to one party, but the other party should be allowed (although not in general required) to manceuvre at an earlier time'. This is so because the second party is still required to take action under Rule 2 I when the situation has deteriorated through the mancuvre of the giving-way vessel. Consequently, responsibility implies freedom to act in time to prevent the situation deteriorating. 3

As I have demonstrated, 4 in any situation one may distinguish two sectors, a forbidden sector in which any course steered would bring the vessels closer than a certain permissible distance, and a permissible sector in which any course steered would not bring the vessel within this distance. Since the stand-on vessel has its course and speed severely restricted by Rule $2 \mathrm{I}$, the permissible sector is clearly defined 4 for the give-way vessel and, consequently, if the second party also takes action (under Rule $2 \mathrm{I}$ ) when the encounter develops beyond a certain limit, the permissible sector implied by her steadiness of course 
and speed no longer applies; it is the same if she is allowed to mancuvre at an earlier time.

The amendments suggested by Captain Kemp do not meet this situation, i.e., the disappearance of the permissible sector defined by the steadiness of course and speed of the stand-on vessel if she also takes action. The only way then to guarantee collision avoidance is to specify the proper permissible sector for both vessels. When vessels are in sight of one another, the sector can be defined by the bearing limits $30^{\circ}$ port and $150^{\circ}$ starboard, 1 i.e., every vessel shall keep course with bearings greater than $30^{\circ}$ port or $150^{\circ}$ starboard.

In my view, therefore, the amendments with regard to the give-way vessel would be at the end of Rules 19 and 24 as follows: ' . . shall keep out of the way by altering course, if necessary, to a bearing greater than $30^{\circ}$ to port or $150^{\circ}$ to starboard.'

With regard to the stand-on vessel, the amendment to Rule 2 I would be '. . may keep her course and speed, or take the proper action to avoid collision by altering course to a bearing greater than $30^{\circ}$ to port or $150^{\circ}$ to starboard', instead of the words 'shall keep her course and speed'.

The specific action required for the stand-on vessel can be established as recommendations embodying the following rules of manœuvre:

(a) Crossing situation. Increase bearing to $90^{\circ}$ port; if this action is not sufficient, increase even to a $180^{\circ}$ bearing.

(b) Overtaking situation. Alter course to a $180^{\circ}$ bearing.

It is easy to see that by steering each vessel within her respective sector a safe passing is guaranteed, and with the above rules of manœuvre the situation that develops is the best suited to the manœuvre of the give-way vessel when her action is late.

Finally, it is important to emphasize that with the Sector Rules we have a universal system, because they apply when vessels are in sight of one another and also when using radar in fog. 3

\section{REFERENCES}

1 García-Frías, J. (1958). ¿Se pueden simplificar las Reglas de Rumbo y Gobierno? Oficemo, May $195^{8}$.

2 García-Frías, J. (1960). Anti-collision radar sectors. This Journal, 13, 316.

3 García-Frías, J. (1964). Radar versus Derecho. Revista Española de Derecho Marítimo, July-September 1964 .

4 García-Frias, J. (1965). The sector rule and the collision problem. This Journal, 18 , $14 \mathrm{I}$.

\section{Mr. F. W. Fricker (United States Naval Oceanographic Office) writes:}

One point that I think both Captain Wylie and Commander Clissold missed in their comments is the fact that Captain Kemp specifically stated that Case Il (proposed Rules) was not applicable in fog. Incidentally, in so stating the author obviously casts doubt on his suggestion that paragraph 4 of the Preliminary to the Steering and Sailing Rules would be redundant.

The essence of Captain Kemp's proposed Rules, as I see it, is that Rule 21 requires the privileged vessel to manœuvre when an encounter develops beyond a certain limit and that many consider the limit to be too late. $\mathrm{He}$ 
proposes that the privileged vessel be permitted the option to manouvre at an earlier time. This proposal has merit but, in his amended Rule $2 \mathrm{I}$, determination of the limit would still rest with the individual. This, I believe, is risky inasmuch as it could easily lead to the opposite extreme, that is, where a stand-on vessel exercises her option too early. This could conceivably change the entire complexion of an encounter.

Perhaps an amplifying sentence could be added to the proposed Rule 2 I, but here, as in the case of the existing Rule $2 \mathrm{I}$, delineation of a precise limit would be most difficult to express.

\section{Captain W. Burger and Captain A. G. Corbet write:}

We agree with and endorse the comments on Captain Kemp's suggestions made by Captain Wylie and Captain Azad, especially concerning the proposal that Kemp's rules could be obeyed by vessels out of sight of one another. The wording of Rules $\mathrm{r}_{\mathcal{7}}$ to 24 implies, without doubt, that the vessels concerned in an encounter must identify each other's type before determining which Rule applies and what action should be taken.

Any action carried out by a vessel in poor visibility to avoid a close-quarter situation with an unsighted vessel or object which has been detected by radar, should be such that the 'hazard' causing the echo will be avoided should it be a power-driven vessel with an efficient radar, or a power-driven vessel without radar, or a hampered vessel with or without radar, or any type of vessel with a defective or maladjusted radar, or anything else one is likely to encounter at sea, e.g., an iceberg, a buoy, an oilrig, \&c.

A power-driven vessel, under command, in deciding what action to take to avoid a close quarter situation with an unsighted vessel or object, which she has detected by radar, could try employing Kemp's general rules of action, i.e., avoid crossing ahead of a moving vessel on the starboard side and avoid crossing astern of a moving vessel on the port side, and the action taken should be such as to produce an anti-clockwise changing bearing. In many cases these general rules are acceptable but, there are several, and not exceptional, cases where the rules could not be applied. For example: An echo is detected on the port side; the bearing of the echo may be steady or changing very slowly in a clockwise direction. To avoid this vessel, own ship would have to alter course to starboard and/or increase speed in order to produce an anti-clockwise changing bearing and in order to avoid crossing astern of the other vessel. Often, in this type of case, an increase of speed would be imperative for own ship to succeed in crossing ahead of the other vessel's bow, should the latter happen to keep her course and speed. It might, of course, be undesirable for own ship to increase speed in poor visibility for a variety of reasons, e.g., if she happened to be in a region where small craft, difficult to detect by radar, can be expected to be met at short range. It might even be impossible for own ship to increase speed because she is already proceeding at her full speed, which she had considered to be moderate previous to the detection of the other vessel on the port side. Now that own vessel has determined the risk of a close quarter situation developing with the vessel she has encountered, she might consider her full speed to be immoderate under the new circumstances and be anxious to reduce speed; but Kemp's rules would seem to forbid this because a reduction of speed would produce a clockwise changing bearing. 
Another example of a case where the suggested rules introduce indecision is when encountering a vessel in fog, bearing fine on the starboard bow on an opposite and parallel course to own ship, as near as can be judged from the radar plot, and shaping to pass too close for comfort. In order to change the slow clockwise changing bearing into a fast anti-clockwise bearing it would be necessary to alter course to starboard and pass ahead of the oncoming vessel.

In clear weather with vessels in sight of one another, Kemp's suggested rules could provoke a case where initially both vessels take the appropriate action to avoid a collision and then, having seen each other taking action, each vessel could decide that the other was taking sufficient action by herself and so both might resume their original courses and/or speeds simultaneously, and too soon. An advantage of one of the vessels keeping her course and speed, as is required by the present Regulations (excepting Rule 18 ), is that each vessel can see the effect of the action of the giving-way vessel.

In conclusion we would like to say that we feel that the new i 960 Regulations and the Annex to them are, apart from a few small points which we shall not mention here, about the best that can be formulated at present, certainly as far as the use of radar is concerned. The multiplicity of situations which can arise when encountering a vessel in fog make the formulation of firm rules of action difficult. Hence it is essential that the Rules should be flexible and that only general guidance should be offered to the mariner, as is done in the Annex to the new Regulations. At present only experience-at sea and on radar simulator courseswill help the individual mariner in determining what is meant by some of the terms used in Rule $\mathrm{I} 6$ and in the Annex, e.g., how to decide what is a moderate speed, or a bold alteration, or a close quarter situation, or good time, \&c.

\section{Mr. E. S. Calvert comments:}

Perhaps a few observations and suggestions from a human factors engineer who has worked on the theory of collision avoidance and has been concerned with applying it to the Rules of the Air may be of interest to seamen.

The Rules of the Air are in principle the same as those of the sea, i.e., they assume mutual detection, and require one party to manœuvre and the other to stand-on. Since the field of view of the aircrew seldom covers more than a quarter of the enclosing sphere, and since they have many jobs to do which prevent them from keeping continuous watch, the assumption of mutual detection in the air is based mainly on hope. It follows that the problem of the airman is very similar to that of a seaman using radar in restricted visibility. Work originally done for the benefit of airmen can therefore be applied to the problems of seamen; Captain Kemp's discussion of how this might be done is, as Captain Wylie says, admirable.

The question is whether a set of rules, applicable to all power-driven vessels, whatever their speed, and to all sightings, whether visual or radar, can be devised to cover all circumstances, i.e., those in which each party can assume that detection is mutual, and those in which neither can assume this. The answer is that a solution along the lines proposed by Captain Kemp (and by Rear Admiral Gauw in 1955$)^{1}$ presents no difficulty, mathematically or operationally, for 'risks of collision' defined as in the second of the preliminary paragraphs to the Steering and Sailing Rules. The definition given there assumes that the question of whether or not the compass bearing is in fact changing can be ascertained; in other words 
the existing Rules, strictly speaking, cover only the rare collision situation, i.e. the case which divides the multitude of encounters in which the sightline is in fact rotating in one direction from the multitude in which it is rotating in the other direction. In the air the closing speeds are, in general, so high, and the visual pick-up range so short, that the real collision situation cannot be ascertained at ranges which are useful for manœuvring, so any aircraft which manœuvres is usually making a random change. The seaman is very much better off in these respects, and with proper predictive procedures can ascertain the collision situation accurately enough for rules to be of considerable practical value, provided they are logical and easy to apply. The next step, and probably a far more difficult and controversial one, will be to work out acceptable tactics for those numerous situations in which a small but 'appreciable' change in bearing is detected.

The wording proposed by Captain Kemp for Rule 22 requires one vessel, A, to 'avoid crossing ahead' and the other, B, to 'avoid crossing astern'. This requires that each, by his own action, shall achieve the end result aimed at for the combined manœuvre of A and B. As Captain Wylie makes clear, this cannot be made a legal requirement, because each may cancel the manœuvre of the other, or may fail to manouvre in the hope that the other will achieve the end result by himself. The difficulty can be removed by a change in wording, and may well be that the wording proposed below does indeed reflect the intentions of Captain Kemp. The change is that $A$ should be required to manœuvre so that she would cross ahead of $B$ if $B$ stood on, and that $B$ should be required to manœuvre so that she would cross astern of $A$ if $A$ stood on. The difference is vital when it comes to apportioning the blame when a collision occurs; mathematically it is exactly equivalent to requiring a land vehicle to keep to the right side of the road, 2 whereas Captain Kemp's wording is equivalent to requiring land vehicles to pass left to left. The effect of this change is to require each vessel to contribute to the desired end result independently of what the other does; not to mancuvre is equivalent to hogging the middle of the road. A vehicle in the middle of the road may not cause a collision, but if a collision occurs the driver will have to explain why it was not on its own side. This principle works well on land, and there would seem to be no reason why it should not work at sea.

If this is accepted, then the basic rules for power-driven vessels would be three; these would read something as follows:

(I) A vessel which detects another vessel, by whatever means, approaching on a bearing forward of the beam in such a way as to involve a risk of collision, shall make alterations to course or speed or both in such a way that the combination of alterations would produce anti-clockwise rotation of the sight-line if the other vessel stood on.

(2) A vessel which detects another vessel, by whatever means, approaching on a bearing abaft of the beam, in such a way as to involve a risk of collision, may make alterations to course or speed or both in such a way that the combination of alterations would produce anti-clockwise rotation of the sight-line if the other vessel stood on.

(3) In restricted visibility a vessel equipped with radar shall keep continuous radar watch. If another vessel is detected approaching on or near the port beam, then speed shall be reduced before the range has closed to $x$ miles. The risk of collision shall then be assessed (at the reduced speed) and action taken in accordance with (1) and (2). 
These rules, like the existing ones, do not face the question of what is to be deemed a risk of collision; that, however, is a question of tactics and procedure, and must be left for another day. It is also obvious that in restricted visibility a vessel not equipped with radar can detect a risk of collision only at a restricted range, and must therefore behave much as it does under the existing rules. It is, of course, highly desirable that radar displays are such that each party can see at a glance the direction of rotation which each is producing. In other words detection of the separate rotations should be mutual, immediate and easy. If stabilization is available there is no technical difficulty in doing this. (3)

The practical effect of Rule ( 1 ) is substantially the same as that of the existing Rules in unrestricted visibility. The difference is that the head-on encounter ceases to be a special case, and that there is no trouble at the boundary between turning to port and turning to starboard, or at the boundary between increasing speed and reducing speed. In the first case, a turn, whether to port or to starboard, will produce the same rotation; in the second case a speed change produces no rotation. The mariner therefore has as much freedom of action as the geometry allows, much greater than under the existing Rules. Rule (2) means that a vessel which is being overtaken is not required to manœurre, but is not debarred from doing so if the other vessel is considered to be cutting things too fine. Rule (3) ensures that anti-clockwise rotation can be produced when the bearing of the threat is such that a turn, whether to port or to starboard, would produce clockwise rotation, and so reduce the contribution which the other vessel should be making. To find out what alterations will produce anti-clockwise rotation, as defined in (1) and (2) above, the mariner merely has to orientate a simple mancuvring diagram (the same for each), and read off the values indicated. In the case of turns, the values indicated 3 are the maximum which are free from any element of self-cancellation ; $^{2}$ smaller values will, of course, be used on most occasions. An improvement would be to make Rule (I) apply to an angle a little more than $180^{\circ}$, say $200^{\circ}$; Rule (2) would then apply over an angle of $160^{\circ}$.

From what has been happening during the past 15 years, it would seem that the marine world first regarded radar as a direct substitute for eyes; under the existing visual rules the other vessel had to be 'carefully watched' with a 'seaman's eye', and it was therefore assumed that the radar display had simply to be watched. When it was belatedly discovered (by some) that simple watching was not enough, the status of radar for collision avoidance was legally reduced to that of a proximity warning device on a footing similar to that of a fog horn. As a result, radar traffic is now required to crawl in restricted visibility. To an outsider, this seems to be a very defeatist attitude to take to radar, because, in all respects except one, radar is far better than eyes, provided that the rules are simple, the predictive procedure is correct, and the display has an anti-collision mode. The fact is that seamen have not been given the tools to do the job. A human factors engineer may, perhaps, be allowed to feel sympathy for those who become scapegoats for this unhappy state of affairs, but the ball is (literally) in their own court. Incidentally, an instructional film is available showing the theory on which this system is based.

\section{REFERENCES}

1 Gauw, J. A. (1955). Radar and collision at sea. This Journal, 8, 178.

2 Calvert, E. S. (1962). Mathematicians and navigators. This Journal, 15, 333.

3 Calvert, E. S. (1961). A comparison of two systems for avoiding collision. This Journal, 14, 393. 


\section{Captain Kemp replies:}

I should like to answer Captain Wylie's criticism of my suggestions point by point. First, my proposals are intended not only to improve the situation with regard to hampered vessels, although they are certainly intended to do this, but also to improve the present unsatisfactory situation when vessels of greatly different manœuvring capability are parties to an encounter. This type of encounter is becoming more and more frequent and the danger is reflected in the statistics, as Mr. Fricker has pointed out in the July issue of Proceedings of the Merchant Marine Council.

Secondly, the words 'a vessel which takes action to avoid collision' refer to any vessel which, because of the risk of collision with another vessel, takes an action which it would not otherwise have taken in the normal course of navigation. This does not seem to me a particularly difficult interpretation and does of course include vessels which attempt to increase a passing distance. Inhibition of giving more sea-room without any convention as to how it should be given may be a most significant aspect of my suggestions. It is, of course; seamanlike to 'give more sea-room' in many cases of encounter, but too often in the past this has resulted in a collision by cancelling the other vessel's manouvre. It is vitally important that 'more sea-room' should be given in the right direction, or not at all.

Thirdly, under the proposed Rules the problem of deciding whether action is necessary is still the responsibility of one ship, and if risk exists then that ship is obliged to take action. Any action which may properly be taken by the other vessel will serve to increase the miss distance. If in case III, which Captain Wylie quotes, a steady or nearly steady bearing is observed by the overtaken vessel then an alteration of course to port will not cause him to 'impale himself on the other's bows' but will in fact enable him to cross ahead with a greater miss distance than if he had stood on. It must be borne in mind that the alteration to port is only a permissive action. In cases of doubt the overtaken vessel has only to maintain course and speed and the situation is clearly no worse than under the present Rules. A similar argument holds good in marginal crossing cases.

Fourthly, I cannot agree at all with Captain Wylie's defence of Rule $2 \mathrm{r}$. This rule works when only two vessels are involved and there is plenty of time for manœuvre. In a multilateral situation it frequently has to go by the board, as for instance when three ships are converging from roughly equidistant directions. All three are obliged by Rule 19 to take action but there is no convention to ensure that it will be effective. An alteration of course to starboard by any of the ships would be a positive action but a reduction of speed (allowed under the present Rules) would be a negative action tending to cancel the starboard alteration by the adjacent vessel on the port side.

When time is short, Rule 2 I seems to me to invite danger. Even cargo ships with speeds of 25 knots are now in service and large tankers are common with speeds of 16 or 17 knots, so that approach speeds in an encounter may be of the order of 40 knots. If a sighting is made at 3 miles and it takes 90 seconds to estimate the collision risk, there remain 3 minutes for any manœuvre which might be necessary. In this sort of situation it is suicidal for the more manœuvrable of the two vessels to maintain course and speed as Rule 21 would frequently require. The escape clause is unsatisfactory because it leaves the possibility of manœuvres cancelling. Rule 2 I was adequate when the average ship was I 2 knots and I 2,000 
tons. I consider that it is a dangerous rule to retain for the future, or even perhaps in present conditions.

Finally, I would agree with Captain Wylie that the situation in fog under the proposed Rules is not entirely satisfactory, because at close quarters the requirements of Rule 16 take precedence over Rules 1 7-24. I would still claim, however, that the proposed Rules are a step forward because the uncertainty as to manouvre, which exists in poor visibility under the present Rules, is universal. Under the proposed Rules the uncertainty is restricted to the close quarter situation when any sort of manœuvre would be fraught with danger; at long range when action may be desirable the Rules give valuable guidance as to what this should be. It is true that a close quarter situation cannot be precisely defined but then neither can such a term as 'poor visibility'. Certainly further work needs to be done on this aspect of the Rules.

I may not fully understand Captain Azad's objections, but in his first two examples I do not see why ' $A$ ' cannot cross ahead of ' $B$ ', even if ' $B$ ' does not manœuvre, simply by altering course according to the Calvert diagram at right angles to the sightline. Ship ' $A$ ' is, of course, obliged to manœuvre under the Rules and if ship ' $B$ ' decides upon one of the permissive manœuvres it will result in an increased miss distance. I would agree however that it might be well to exempt encounters between sailing ships from the provisions of my suggested Rule 22.

In Captain Azad's third case I believe that, provided it is made in sufficient time, an alteration to port by ship ' $B$ ' is a perfectly seamanlike manœuvre because an alteration to starboard might cancel any last minute manœuvre by ship ' $A$ '. If ship ' $B$ ' has left his manouvre too late then a small reverse manœuvre under Rule 27 to put ship ' $A$ ' right astern would probably be the best answer. In any case I cannot regard the encounter he illustrates as presenting much danger if ship 'B' does the most likely thing and maintains course and speed.

I would also point out that the present Rules are cooperative and that in a great many cases they fail one or more of Captain Azad's tests. In fact I cannot think of any type of encounter in which the present Rules do not fail his second test. The failure of one vessel (i.e. the giving-way vessel) to take action would always increase the danger.

I believe that I am on the same general course as Commander Clissold and I agree in the main with his comments. A minor disagreement is that I do not, in general, object to prolonging a crossing. Prolonging an encounter, either by altering course or reducing speed, means that the approach speed between the ships is reduced-which is surely a safety factor. It is certainly better to have a slowly developing crossing than a rapidly developing collision.

Commandant Oudet, as always, writes constructively and with much insight. The main point at which we appear to differ may be due to a difficulty of translation and concerns division of responsibility. Under my suggested Rules responsibility for manœuvre remains exactly the same as under the present Rules, i.e. Rules $17,18,19,20,24,27$ and 29 are unchanged. Apart from end-on cases, only one of the two parties to an encounter is obliged to manœuvre and the other, as Commandant Oudet says, is privileged. Under my suggested Rules, however, this comprises not only the sometimes doubtful privilege of maintaining course and speed (possibly into a dangerous situation) but also the privilege of altering course and speed according to a specified convention if this is thought to be a better option. 
As Commandant Oudet points out with illustrations, some vessels, for common-sense reasons, do not comply with the present Rule $2 \mathrm{I}$. It seems to me that if it is common sense and frequent practice not to comply with a rule then that rule should be changed. If escape rules such as 27 and 29 have to be invoked as a matter of every day usage there is clearly some fault in the main body of the Rules.

A further point which Commandant Oudet mentions, and which he has brought out many times in his work on the analysis of collisions, is the dangerous situation when one party to an encounter thinks the line of sight is rotating clockwise and the other thinks that it is rotating anti-clockwise. Insistence that if either or both of the vessels manœuvre they should do so to cause an anticlockwise rotation of the line of sight, whether or not the other vessel maintains course and speed, seems to me to remove the greatest danger which is that one vessel may make a manœuvre which cancels that of the other. The preference, expressed in the 'Use of Radar' annex to the present Rules, for an alteration to starboard rather than to port is an admission that the suppression of clockwise rotations is necessary.

M. Hugon clearly is not very happy about the implications of the present Rule 2 I but I would suggest that my proposals do much to resolve the difficulties which he mentions. I agree that no set of Rules can provide for every possible case but I believe that any set should provide for as many cases as possible, so that very few are left to be covered by Rule 29. This rule, as M. Hugon says, relies on the common sense of the sailor; but when it has to be decided whether to alter course to port or to starboard, or whether to increase or decrease speed, common sense may not be enough. If two cars are approaching head on, common sense will not tell the drivers which way to turn; this information must derive from a convention or rule which depends upon the country in which they are driving.

I agree with Captain García-Frias in his dissatisfaction with the present Rules but I do not agree that the solution which he proposes is entirely practical. However, although I do not think it is possible to legislate for his sector rules it would seem that nothing in my suggestions would prevent a vessel using a version of the sector rules unilaterally.

Mr. Fricker's comment makes it necessary to clarify the phrase 'option to manœuvre at an earlier time' in my original proposals. I did not intend that there should be any limit to how much earlier this might be ; in fact, if the privileged vessel decides to take action rather than stand on then, in general, the earlier action is taken the better. It is true, as Mr. Fricker says, that such action could change the entire complexion of an encounter, but since a collision risk exists initially this is surely the object of the exercise.

Captain Burger and Captain Corbet mention several points which need comment. In their first paragraph they state correctly that a party to an encounter must identify the other vessel's type before determining which rule applies. They also state that identification is necessary before deciding what action should be taken; this is perfectly correct under the present Rules but not under my suggested Rules. This is because, for a given bearing of a threat, the alterations of course and speed which are permitted to a privileged vessel are identical with those which are prescribed for a vessel which is required to take action. In cases of doubt therefore, as for instance in fog, a vessel may take effective action whether the threat is any of the objects mentioned in Captain Burger and Captain Corbet's second paragraph. This very important point is the key factor which allows my suggested Rules to be used when only radar contact is made. 
In their third paragraph it is suggested that the presence of a third vessel may make it difficult to obey my proposed Rules; of course it may, although not as often as it does under the present Rules. The example, a vessel in fog detected by radar on the port side, is certainly a difficult one-the present Rules allow random manœuvres until a dangerously close quarter situation occurs. What my suggestions set out to do is to bring some order to the manouvres so that a close quarter situation is less likely to occur. It is conceded that they will not always succeed in this but I believe they will succeed more frequently than the present system, or lack of system.

The second example concerns vessels meeting end-on, or nearly end-on, and is covered, as at present, by Rule 18 which, as under the present Rules, overrides Rule 22. For end-on or nearly end-on cases 'crossing ahead' or 'crossing astern' has very little meaning since a small yaw on the part of one vessel will take the other across its bow. A slight alteration of wording would be sufficient to make this quite clear in my proposed Rules, but it is not provided for in the present Rules and I would hardly think it necessary.

Captain Burger and Captain Corbet's last point is that under my proposed Rules each party to an encounter might alter course and then resume their original courses too soon. This I would think most unlikely since responsibility for taking action is vested mainly in one vessel. It does not seem to cause difficulty under the present Rule i 8.

Mr. Calvert's comments are clear and well reasoned, but to change to his suggested Rules from the present Rules would represent a very large jump and, as $M$. Hugon points out, far-reaching changes of this sort must for practical reasons be achieved in small steps. What I have tried to do is to make the least possible alteration to the present Rules. Mr. Calvert's manouvring diagram may be stuck on a ship's windscreen, as he himself has suggested, to give guidance as to effective action when a collision risk exists. His ideas might well be the goal towards which the Rules could evolve in a further series of acceptable steps.

The current Rules have served us well in the past. They do not appear to be serving us so well in the present and it seems likely that they will become less effective in the future. Captain Wylie began his remarks with the hope that a lively and useful discussion would ensue. I hope that it may continue in this spirit of constructive criticism. 